\title{
Gaining favorable identities of Iranian EFL teachers: a single case study of transition from elementary schools to universities
}

\author{
Farzad Rostami ${ }^{1}$, Mohammad Hosssein Yousefi ${ }^{{ }^{*}}$ (D) and Davoud Amini ${ }^{2}$
}

\author{
* Correspondence: mhh.yousefi@ \\ gmail.com \\ ${ }^{1}$ Department of English Language, \\ Bonab Branch, Islamic Azad \\ University, Bonab, Iran \\ Full list of author information is \\ available at the end of the article
}

\begin{abstract}
Adopting the self-concept framework as a lens and interpretative case study as a methodological tool, the present study set out to examine how the professional identity of an elementary school teacher is socially (re) constructed while his transition from teaching at elementary schools to teach at universities. The design of the study was the intrinsic case study. The focal participant was an assistant professor of TEFL who has been teaching in elementary, middle, and high schools prior to starting his academic work 10 years ago. For the purpose of the data collection, in-depth interview was conducted. Another source of the data was the participant's stories, as well as the diaries he had kept over the years. For the data analysis, thematic analysis was employed. Results indicate that the transition was seen to be in parallel with the transition from lower identity perception to higher identity perception. The transition can be best expressed in terms of identity promotion. The results indicate that the transitions were two main and noticeable ones. The data analyses also indicate that three themes, including personal-self, social self, and learners were the driving forces for the case's professional identity development. The study has a number of implications for teacher education, policymakers, and teachers.
\end{abstract}

Keywords: Professional identity, Promotion, Teachers, Favorable identities, Selfconcept

\section{Introduction}

Recently, there has been a surge of interest in teachers' professional development (Pennington 2014; Reynolds 2015; Sinha and Hanuscin 2017; Tran et al. 2017; Yazan 2018). Reynolds (2015) attributes this fact to a move away from the group (and associated identities) being viewed through a prism of anticollectivism - where groups were sidelined because they were considered somehow flawed or inherently inferior to individual understanding.

The research findings, so far, indicate that identity is discursive and experiential and is constantly negotiated by teachers in relation to their lives and learning experiences, teaching colleagues, professional mentors, students, and their teaching environments

(c) The Author(s). 2020 Open Access This article is licensed under a Creative Commons Attribution 4.0 International License, which permits use, sharing, adaptation, distribution and reproduction in any medium or format, as long as you give appropriate credit to the original author(s) and the source, provide a link to the Creative Commons licence, and indicate if changes were made. The images or other third party material in this article are included in the article's Creative Commons licence, unless indicated otherwise in a credit line to the material. If material is not included in the article's Creative Commons licence and your intended use is not permitted by statutory regulation or exceeds the permitted use, you will need to obtain permission directly from the copyright holder. To view a copy of this licence, visit http://creativecommons.org/licenses/by/4.0/. 
(see for review Beijaard et al. 2004). The notion of identity has been defined in different ways. For example, Pennington's (2014) definition of teacher identity is as follows:

Teacher identity is a construct, mental image, or model of what "being a teacher" means that guides teachers' practices as they aim to enact "being a teacher" through specific "acts of teacher identity."(p. 17).

Moreover, Beijaard et al. (2004) provided the following definition:

"Teacher identity refers not only to the influence of the conceptions and expectations of other people, including broadly accepted images in society about what a teacher should know and do but also to what teachers themselves find important in their professional work and lives based on both their experiences in practice and their personal backgrounds." (p. 108).

The notion of identity has been seen from diverse perspectives and lenses. For example, American psychologist, Erikson (1968), one of the earliest psychologists interested in identity, highlighted two types of identity - ego identity and cultural or social identity. Ego identity refers to a conscious sense of self as unique as well as continuity of experience. A strong sense of self is argued to emerge during adolescence and is central to well-being. One way to think about social identity within this framework is that it captures the extent to which there is a supportive community that validates the identity and gives it strength (e.g., "greater validation of social identity can nurture ego identity," Côté and Levine 2002). Erikson argues that "[Ego identity's] most obvious concomitants are a feeling of being at home in one's body, a sense of 'knowing where one is going,' and an inner assuredness of anticipated recognition from those who count" (Erikson 1968, p. 165).

FFrom a different perspective, Mead (1934), emphasizes a philosophical stance toward identity, where other people's perceptions and reactions are argued to shape one's self-view in a dynamic way. A generalized conception of one's own self develops through experience and observations of how others act toward the self (the so-called 'looking' glass self). The self is social or public in that it contains the internalized reactions, expectations, and judgments of others.

Nevertheless, Akkerman and Meijer (2011) adopted a poststructuralist and postmodernist worldview toward identity. The view sees several recurring characterizations of teacher identity: the multiplicity of identity, the discontinuity of identity, and the social nature of identity. Although the researchers have accepted that the ego's identity perspective is close to the findings, the current study goes beyond in line with what Mead (1934) perceives of identity. It seems like that identity is a silent and static perception of oneself that is reconstructing dynamically by getting influenced by the factors like self-development motivation, other's actions toward the self, and the continuum of social expectations.

\section{Literature review}

Previous research illustrates how professional identity is formed by the interplay of different spheres of life, including those outside work and education, and that some of 
these spheres play a bigger part depending on the time and situation (Nyström 2009, p. 65). Akkerman and Meijer (2011) pointed out that identity should be defined as a dynamic process of negotiating and interrelating multiple I-positions in such a way that a more or less coherent and consistent sense of self is kept throughout various participations and self-investments in one's (working) life.

One of the recurring themes in the literature on teacher identity is its discontinuity. It signifies that teachers 'professional identity is not fixed and often changes (Beijaard et al. 2004). More recently, research on teachers 'professional identity has shifted its focus towards the dynamic process of its formation, negotiation, and/or renegotiation (Tran et al. 2017).

In an empirical study, Liu (1999), for example, showed how seven non-native speaker teachers differed in their understandings and acceptance of this label, and how some of them navigated through the native speaker and nonnative speaker identities depending on their contexts. As Liu defends, 'people can have multiple social identities.

Beijaard et al. (2000) examined 80 experienced secondary teachers' perceptions across subject areas about their professional identities along with three knowledge domains: subject matter, didactic, and pedagogical. In their study, all teachers viewed subject matter knowledge to be most important at the start of their practice, and later, most incorporated more didactical knowledge. The case of subject matter identity was examined by Beijaard et al. (2000). The study indicated that the notion of identity and subject matter identity are separate entities. Little is known about how the teachers' professional identity is constructed and reconstructed over a more extended period of time, over two decades or so. Also, little is known whether one can think of any stages or boundaries in teachers' professional development in longitudinal studies like the current one.

\section{Theoretical framework}

Self-concept refers to a person's self-perceptions formed through experience with and interpretations of one's environment (Shavelson et al. 1976). The experiences make the person get more realization of one's potentials and competencies to act in the future differently. Thus, self-concept can be regarded as the self-perception about one's own abilities (Marsh and Martin 2011). Understanding capabilities leads to better performance. Self-concept is regarded as a highly significant and determinant factor in that it is closely associated with people's academic achievement (Branden 1994; Marsh and Martin 2011).

Some key features contribute to promoting self-concept such as internal (personal) and external (social) motivations, academic choice, and coursework selection (Marsh et al. 1999). The early shaping of self-concept in a person leads to shaping long objectives in the recursive form to achieve in mind, primarily when academic achievements are aimed. It goes in line with McNaughton and Billot (2016) notions that academic identity is constructed through a recursive and iterative process. Marsh and Yeung (1997a, 1997b) found that academic achievement and coursework selection were all highly correlated. Their findings made them innovate a new term of academic self-concept that was a much better predictor of subsequent coursework choice. For the case in the current study, the coursework, English language teaching, selection underpins the 
developing self-concept, achieving an academic position, and constructing academic identity.

The framework also covers the notion of transition that emerged from the research themes. The transition motion in the self-concept framework occurs among students. Valentine and colleagues (Valentine and DuBois 2005; Valentine et al. 2004) found that transition among school learners had not improved their self-belief; however, the concept of self-belief is strong when it is based academic measurement. There is a probability that cognitive development among learners plays a more active role in their achievement. The case that we studied in the current research played a role of teacherlearner who has grown metacognitively.

\section{Method}

For a qualitative researcher, a 'case' can be seen as a bounded system comprised of an individual, institution, or entity and the site and context in which social action takes place, the boundaries of which may not be clear and are determined by the scope of the researcher's interests (Hood 2011).

The main objective of this paper was to discuss the processes of (re) construction of identity, identity enhancement, and professional identity in a teacher's life during his teaching practices. The interview questions dealt with the processes of transformation of identity, and the mechanisms behind the changes. Thus, we make a contribution to the level of literacy and knowledge in reshaping professional and social identity. We retrospect to the teacher's experience as a life story in a way he can better elaborate on the process of change. The semi-structured interview, teacher's story and diaries direct us to find the answers to the following questions:

1. What stages/ transitions involved in primary school teachers' promotions to university professors in the Iranian context?

2. What factors motivate Iranian professional development through teaching primary schools to teach at universities?

\section{Design}

For the current qualitative research, the single case study was adopted to gain a deep understanding of the case itself (Stake 1995). This intrinsic case study is an individual whom the researchers desired to explore. Qualitative case studies are preferred by researchers who believe that 'reality' is multiple, contradictory, changing and that the researcher inevitably becomes part of the study (Merriam 1988). The tendency toward utilizing case studies is growing as there is no attempt at all to generalize from the case being studied, compare it to other cases, or claim that it illustrates a problem common to other, similar cases. According to Hood (2011), a quick look at the tables of contents of the leading journals in the fields of linguistics and language teaching reveals a steady trend in recent years toward the use of a case study in applied linguistics and Teaching English to Speakers of Other Languages (TESOL) research. This trend, he believes, reflects the emergence of a new kind of researcher - one who seeks to understand the world not only in terms of the generalities produced by quantitative methods but also through a close and extended analysis of the particular. 


\section{The case}

The only participant in this study as a focal teacher was Sayeed (a pseudonym), 44, who has been teaching for about 20 years. Selecting him as our focal teacher was significant as he has had different transitions in his professional life. He started teaching elementary schools in 1999. Between 2000 and 2008, he had been teaching English at middle schools in his hometown, Miandoab, Iran. Since 2009, he began teaching English at high schools. His academic life began in 2010. Since then, he has been a faculty member in an English department. Over his teaching years, he had a diversity of professional identity feelings and emotions; he felt demotivated and discouraging at times, felt motivated and determined the other times, he had felt highly motivated and hilarious. People, in his hometown, attribute different identities to him, for a group of people he was an elementary school teacher, for another group of the community, he has been recognized as a high school teacher. Still, for a large number of people, he is a university professor.

The focal teacher was selected because the case can enrich our understating of teachers' professional identity development with different transitions and unique pathways of professional development. This process is scrutinized well in line with the aim of our research. The participant was consented to attend the interview, provided the researchers with the diaries he had kept them over the two decades. As the case informed us, he had the diaries from teaching primary schools since 1999. The diaries, he said that, include triggering moments in his teaching, critical incidents and different aspects of his professional development including studying in B. A, M.A. and $\mathrm{PhD}$ as well as transitions from primary schools to middle, from middle school to high school and finally from high schools to being member of faculty .we asked for the most significant diaries on the objectives of the study and he provided us with ten selected diaries. The authors selected three out of the ten diaries. The case's diaries were written in Persian. The lead and the second authors independently translated them into English and discussed the contradictory points. For validation purposes, they e-mailed the translated versions to the participant and he verified them with slight modification. Finally, he was assured that his data and identity would be kept confidentially. The present study is also a valuable source of data for the researchers in so far as it is longitudinal research.

\section{Data collection}

The researchers mainly focused on the questions that cover not only the professional engagement and interaction of the participant with the learners of different ages but also how the dimensions of his work, e.g., research, have developed. Moreover, the way that social and professional identities have been progressing is questioned. The interview took 60 min approximately. The reflective interview between the lead researcher and the case was digitally recorded. The data were broadly transcribed then presented to the participant for more comments; none were made. After the validation of the data by the participant, the original recording was destroyed due to ethical guidelines. To triangulate the data and enhance their trustworthiness, two other data collection tools were utilized; the participant's stories and his diaries he has written for more than two decades. We also elicited the participant's triggering points in his professional 
development through his stories. As pointed out earlier, the authors selected a number of the case's diaries and translated them into English and for validation purposes, we emailed them to the participant to comment on and verify them.

\section{Data analysis}

In line with our aim in conducting qualitative research, we utilized thematic analysis following the guidelines put by Braun and Clarke (2006). Thematic analysis is a sophisticated qualitative tool that helps to research in a precise, consistent and exhaustive manner through recording, systematizing, and disclosing the methods of analysis and detailed enough findings of the study to enable the reader to determine the credibility and validity of the process (Nowell et al. 2017).

Having familiarized with the content of the data, Microsoft Excel 2010 was used to help the researchers code and identify themes (Bree and Gallagher 2016). As we did not have pre-coding in mind, we used axial coding and code description at the semantic level. Then the relationships among the codes were identified and categorized into themes according to the research questions. In order to establish inter-coder reliability (Armstrong et al. 1997), the second author re-read the raw data, noted similarities, and coded them. On the other way, the authors waited a few days, then went through the data and coded them again to gain intra-rater reliability (Saldaña 2016). The similarity and consistency of interviewees' responses were noticeable so that the researchers could find little dissimilarity among the obtained data. Having identified the relationships among the codes, the researchers consented to cluster and collate the codes to themes (see Table 1). The themes were 'defined and refined' to organize them into a coherent and internally consistent account (Braun and Clarke 2006).

\section{Findings}

The findings revealed two stages of transition in the professional life of the case. The transitions have contributed to (re) constructing the identity of the participant. Moreover, the data have found some significant factors that helped the case to exercise transitions. We labeled the factors as our central themes. Themes are formed from the codes that researchers consented on.

\section{Theme 1, personal-self}

The personal-self theme here concerns the inclination and identity codes that the participant discussed during the interview and telling his stories. These factors imply that

Table 1 An overview of the emerged codes and themes

\begin{tabular}{lll}
\hline Themes & Codes & Key terms \\
\hline Personal self & Inclinations & Being a teacher, change the level, sensations \\
& Identity & Lower identity, being bothered, lack of appreciation, subject matter \\
Social self & Identity & $\begin{array}{l}\text { Positive identity, being called differently, more knowledgeable, researcher } \\
\text { rather a teacher }\end{array}$ \\
& adoption & study more, being a professor \\
Learners & School learners & More dependent, having short aims, the only receiver \\
& Collage learners & More independent, teach, do research, \\
\hline
\end{tabular}


internal motivators contributed to the transition. The lead researcher started the interview by "how did it go to be a teacher?" the answer shows the inclination that can be traced to the context he was a primary student in. He replies:

Actually, from the very beginning, I was interested in teaching. I studied my primary school in a rural school, far from downtown. My teacher would ask me to teach my classmates prior to beginning our classes by the teacher. Moreover, my father was an employee of education office. He encouraged me to be a teacher. Last but not least, I enjoyed teaching and instructing others. Even today, I enjoy teaching people.

Teaching gives me a sense of delight and sometimes exultation.

The participant's inclination toward teaching comes back to his childhood. As his story reveals his own personal interest, his primary school teacher, and his father encouraged him to become a teacher in the future. In spite of so many changes in his identity perceptions and diverse transitions he has had in his professional career, the only constant was his love for teaching. This interest never tended to wane during the two decades or so. The participant claimed that he has perceived himself as a musician playing music in an orchestra and enjoys harmony and melody simultaneously.

We questioned the base position of the participant as a novice teacher at primary school. The answer overlapped with social-self, the second theme of the research. The case had considered himself a knowledgeable teacher while teaching. However, he found himself as a passive person that had not been able to expand his knowledge base. He mentions;

I was not under pressure to learn new things; to read the latest papers and books. I was not under pressure to be up-to-date with respect to the latest learning and teaching theories. Most of the techniques I utilized in my classrooms were borrowing from my own primary school teachers, namely two decades earlier.

The case, tacitly, acknowledges that he never enjoyed the conditions he was experiencing as a primary school teacher. However, he confesses that he was not under pressure to read the latest books and papers on teaching. This can be interpreted in a way that he never saw a perspective for personal and professional development. He never thought of acquiring new teaching method based on new theories. This, in turn, reveals the fact that he did not have access to any professional development courses as an inservice teacher. Having no hope for professional development and having no opportunity for professional learning have created adverse conditions for him as a novice teacher.

The transposition of the case is the chief concern of the current paper. The interviewee promoted his degree from school diploma to teaching at Ph.D. program in TEFL. He appreciates his current position as a different and more professional person. He reflected his personal reasons to make the change;

When I was teaching at primary school, I did not have a university degree. While I was teaching in high schools, I held my M.A. degree from a prestigious university in English language teaching. I would send e-mails to distinguished scholars in my 
filed and asked for their views on teaching issues. I was reading the latest scholarly articles on language teaching. I had grown in self-confidence and self-esteem....... The thought never suddenly came to my mind. Rather, you know, the pass to development is an accumulative one. To go forward, you need to do things one after the other in a regular fashion. To me, one progress led to another. You never think of a series of changes and development in your professional life. You think of one step, and one stage and the remaining stages and steps will appear on your way.

Here, the case compares and contrasts his own personal self while teaching at primary schools and high schools. As it was mentioned earlier, the case did not have any hope and opportunity for professional growth and learning while teaching at primary schools. In contrast, he is now pleased with reading the research findings, he has gotten opportunity for development and he has a positive self-image of his identity and career. It seems that his personal-self began to enhance as he goes through different transitions in his career as a teacher.

Furthermore, in one of his diaries, the case has written about the adverse conditions he had felt as a primary school teacher:

Today was one of my toughest teaching days and I suffered greatly for it. when I compare my classes with middle school classes, I come to the conclusion that their students take both the teachers and subject matters seriously. They, in a sense, do not have classroom management problems. They also do not need to warn their students to follow school discipline. As far as I teach in grade one in primary school, my students are sure that they would easily pass the courses. Today, I was very demotivated in the classroom and at home. I think my mental health will undergo terrible change. I should do something that get rid of these challenging conditions. I have two options; either to quit teaching or to change my field of study and teaching. I should teach something more valuable and prestigious in middle school. I should get promotions.

It seems that in the diary quoted, both personal self and social self, have been amalgamated. The motivations behind the case's transition was twofold; to get rid of the adverse conditions of teaching at primary schools and to attain a more favorable social status. When he commented that he would like to teach something more valuable and prestigious, in fact he looks for more positive social position and more favorable professional identity compared to than that of first grade primary school teacher's one.

\section{Theme 2, social-self}

The second theme, social-self, refers to the most significant and external motivators that caused transitions in the participant. The most noteworthy codes that were listed in this theme were lower identity and higher identity that the case perceived from the society as well as the adaptability he made. These dynamics shaped contributed to transit from lower identity to higher positions. The lower identity that the participant had received was bothering. He clarifies; 
They, local people, called me as an Amuzeghar \{teacher of elementary school\}, which connotes lower position, lower identity, and lower knowledge. The people of the village that I was assigned to teach there had the feeling that I was in a lower position and with no university degree had to teach there. Actually, I was bothered by the fact despite my interest in teaching. I wished to pursue my studies and promote to teaching at middle schools.

It is well obvious that the case's inclination to have transitions from primary schools to higher levels were a combination of both internal and external factors. Theme one, provided us with internal factors and this theme, social self, illuminates on the social variables. This story emphasizes the demanding and worse conditions in which the case was assigned to teach. No doubt, his perception of lower professional identity would affect his instructional practices in his role as a primary school teacher. This negative force, at first glance, is a very demotivating force. However, upon scrutiny, the case has been motivated to pursue his studies to get rid of the adverse situation and presumably to gain an acceptable social position.

In theme 1, personal-self, we wrote about the personal reasons that caused the participant to move to the upper position. Under the same interview question he added the social reasons behind the transition;

People had a lower identity position toward me in society. They assumed an inferior identity towards my colleagues and me. I was really bothered by their attitudes. They belittled me and my activities as a teacher. In a sense, I wanted to get a promotion in my identity and win the admiration of my fellow citizens.

Although the attendant liked his job as teacher, he was irritated by the attitude that people had toward him. The point of view was not due to his profession as a teacher, but it referred to the level of giving lessons. It made him wonder if he could heighten the level of teaching. Shifting the stage of instructing not only promoted his identity but also heartened him to think about more transitions.

The participant transited three stages, first from teaching at primary schools to middle schools. The next one was from teaching at middle schools to high schools, and the last one, from high schools to lecturing at university. He thinks differently from these three stages. For him, the transitions are better noticeable as two transitions. He prefers to call these two transitions and stages in his professional life as dramatic and sharp. He constantly compares and contrasts these two stages, both in terms of internal variables like self- concept and satisfaction and external factors such as social position and sense of lower vs. higher identity perception. He goes on to reflect on the characteristics of these two transitions:

In my view, two dramatic changes and transitions have been made in my professional life. The first and foremost transition was from teaching elementary students to middle school students. The significant and noticeable transition was teaching at universities. Teaching at universities has largely affected my own professional identity, feelings, and my position in society. People at the university and in the society call me as "university professor" which connotes lots of positive and prestigious 
concepts; highly educated, intelligent, and prestigious. Adding to these positive points is the notion of subject matter identity. To a large extent, people judge and value you by the subject matter you teach. I teach English language to university students, and teaching English has satisfied my quest for higher professional identity in society. However, the drive for my quest for promotion is not limited to social factors. It is mainly driven by my own personality traits. My sense of achievement, my sense of learning new things throughout my career leads me to go forward. You know my own motivation in learning and teaching never ever was instrumental; it was ALWAYS an intrinsic and integrative one.

Not only lecturing at university but also selecting the right subject matter were conducive to promote the identity of the participant. These two factors were instrumental in shaping highly social identity which the case wished while teaching at elementary school. However, these issues were not mainstays of the identity elevation. Self-perception and the deep desire to learning and achievement were main attributes to gain the hope through various transitions.

The second step of transition changed the participant career, and he feels high identity and satisfaction. This step has differentiated him from a regular school teacher. He claimed; People at the university and in the society call me as "university professor" which connotes lots of positive and prestigious concepts; highly educated, intelligent, and prestigious. Moreover, the participant added that the subject he teaches plays an essential role in constructing his academic identity;

To a large extent, people judge and value you by the subject matter you teach. I teach the English language to university students, and teaching English has satisfied my quest for higher professional identity in society.

At the end of the interview, the participant concluded that a combination of personal and people's attitudes characterize the construction of professional identity. He expressed;

It should be mentioned that people's attitudes and perceptions of your lower identity can trigger your development; it cannot sustain you motivated. As you pass through the developmental path, you need an inner desire to remain highly motivated. This motivation, in turn, will assist you in meeting challenges on your way to professional development.

\section{Theme 3, learners}

The last theme that the participant stated as an external element was learners. The theme is shaped by school learners and college learners' codes. There are some fundamental differences between these two groups of learners and the way they played roles in the transition to constructing a new identity. He differentiates school learners as demotivators and talks about their characteristics; 
Child learners need your ongoing and immediate concern and attention; in a sense, they are not independent learners. Children are not motivated enough and never think of long-term objectives of education. Sometimes, you should push them to learn specific tasks.

One of the motivations behind the participant's transitions to higher levels was the learners he was assigned to teach them. He made distinction between dependent and independent learners he contended that teaching primary school students is a very challenging and demanding task, since they need your day in day out and moment by moment concern and consideration. They learn little without teachers'supervision and scaffolding. However, this is not the case with middle and high school students. They can learn different tasks without teachers' direct supervision. This, in turn, will make teaching a less demanding and more enjoyable task for teachers.

It seems that as the case transited to higher levels, the learners were of help for him rather than hindrance. Here is a case's story:

One day, I was teaching in a far-off village in Northwestern Iran, there were only three classes in that middle school. You know, students constantly compare their teachers with respect to classroom management, knowledge-base and personality traits. I used to ask my students for their anonymous viewpoints on my teaching at the end of the academic year. Having compared me with other teachers, one of my students had written something very interesting and motivating to me: "you are the best teacher I have ever seen! What has happened to you to be a teacher?" his words inspired me greatly. I interpreted his words as having higher expectations of me, presumably to develop professionally, to be a high school teacher, to be a university professor. He must have meant these. I told myself then.

As the case promotes to higher levels, his learners help him rather than bother. It is evident from his story. As the story unfolds, the case has been triggered positively by his learner's comments. Actually, his student's view has inspired him to develop professionally. This highlights the fact that learners can assist teachers to tend to professional development.

In another story, the case talks about high school students:

I could develop close relationships with my high school students. They felt relaxed and free to talk about their personal lives. They easily criticized my teaching and I enjoyed receiving their comments. Sometimes, we played football in school break time.

The case enjoys receiving criticisms from his students simply because he thinks that they are grown in critical thinking. This, in turn, reminds the case that his learners are independent thinkers. They are no longer dependent on his immediate assistance and scaffolding. They can both learn and think independently. This a bright side of the case's professional development. As he transits to higher levels, so do their students.

On the contrary, college students need less attention and work with them. This is because of what the participant expressed; 
Moreover, the majority of my Ph.D. students themselves teach at different universities. This makes me think that I am a teacher educator as well as a social reformist. I think that I am an influential person in my society, not only affecting our education but also our culture. However, the changes are small-scale and local.

This is the acme of his professional development. He has attained the highest teaching level. The case now teaches $\mathrm{PhD}$ students, supervises their dissertations. He is sure that he has achieved the highest possible professional identity feasible for an Iranian primary school teacher. The status that is associated with higher professional identity, higher knowledge, and higher social acceptance form the society.

\section{Discussion}

The results of the present study illustrate a two-stage of the transition of an elementary school teacher. The paper generally talked about a concept promotion of the case. It shows that promotion involves the transition to a higher social position, with higher challenges, higher social expectations, more responsibilities, and a higher level of dignity and prestige.

The case has taken multiphase courses to his professional development; each stage has led him to the next one. Some changes and transitions from one stage to another stage were not sharp and clear-cut. Some others, however, were dramatic and noticeable, either because of the learners involved or by the social position they involved.

\section{The personal-self impact}

In line with the theoretical framework, intrinsic motivation correlates with academic achievement (Marsh and Perry 2005) by the use of transition steps. Having found himself as a passive person wondered the case about the current position and the identity he possessed. The first transition occurred at two levels; education and coursework. The case of the current research realized that the methods he had applied were old, and there was a need to be upgraded. Thus, he decided to study at university to promote academic self-concept.

Moreover, the case has selected English language as his desired major. The reason for selecting English language traced back to the fact that he could notice the major difference between the English classes with other subject matters at his teaching context. English classes were more silent and engaged in doing homework; furthermore, the students were more enthusiastic about learning English language. His choice of the English major goes in line with Marsh and Yeung (1997a, 1997b) that coursework selection partly mediated the effects of academic self-concept in a specific school subject on subsequent academic achievement.

Doing the transition will increase self-confidence and self-esteem with the participant. The finding on improving self-esteem goes in contrary with Baumeister et al. (2005), who concluded "that efforts to boost people's self-esteem are of little value in fostering academic achievement or preventing undesirable behaviour" (p. 84). This contradiction is justified through this matter that Baumeister et al. (2005) had only adapted a unidimensional perspective that included only studies based on self-esteem before 1990. Improving self-belief was encouraging and facilitating the developmental path and reconstructing identity as well as being successful in academic achievements. 


\section{The social-self impact}

Marsh and Martin (2011) consider the social domain as a component of the self-concept. In our study, the social-self is regarded as an external motivator playing a significant role in (re) constructing (academic) identity. The case of our study had perceived a lower identity in comparison with the teachers of upper levels of teaching. Since teaching at the upper levels needs to be specialized in a subject, he selected the English language as the subject matter. It was perceived by the participant that English teachers had been regarded as more open-minded and up-to-date individuals in comparison with other subject-matter teachers. Moreover, they were more respected by outsiders since whenever people had a problem with new gadgets, they referred to English teachers to direct them through English manuals. Thus, the first transition occurred to teach English at high schools. Attending university classes, doing the research, and interacting with teacher educators reconstructed his lower identity into higher identity. The sensation of change in the view of outsiders encouraged the case to follow his education at $\mathrm{Ph} . \mathrm{D}$. level and gain an academic position. Gaining a higher degree of literacy, playing a new social role, and interacting in the new environment contribute to forming a positive social self-concept. As Brookover and Lezotte (1979) claimed, schooling maximizes academic self- concept and academic achievement. The participant's new academic identity is owing to higher schooling in which the perception and expectation of social stakeholders are improving.

\section{The learners' impact}

The role that students played in promoting identity is considered as an external motivator. The learners per se did not act in reconstructing identity; furthermore, the extent of the work that the learners required considered the teacher to work more academically. More cognitively developed the learners, more demanding they are; as a result, the teacher is more engaged in the tasks that acquire more professionalism. The transition from being passive in elementary school to being active academically changed reconstructed his identity from teacher identity to academic identity. At the university level, some learners of the case teach at different universities. This matter deliberated the participant as a teacher educator. Shaping professional identity is partly related to the learners that demand complex tasks like writing research papers. Analyzing the emerged data from the studied case indicated that students' success and satisfaction are in close relationship with self-concept (OECD 2003), actively support academic achievement (Marsh and Martin 2011), and encouraging the educators to improve their academic identity in the current position of transition.

\section{Conclusions}

The current study investigated how the identity of a primary school teacher reconstructed in two stages of transition into new academic identity ultimately. The analysis of the interview reflected that gaining academic identity is challenging. Making the transition from primary school teacher to high school teacher was moving from lower identity to higher identity while the transition to the second step, university professor, has been regarded as a marked shift. Self-perception, social attitudes, and the learners of the case have been contributing factors in reconstructing the case 's identity. Selfconcept, as the chief theoretical framework of the research, has been crucial in reshaping new professional identity. The component of self-concept, e.g., internal and external 
motivators and coursework selection, played an inspiring role in the process of achieving professional and academic identity.

The results show that teacher professional identity formation can be affected by a combination of both internal variables such as self-esteem, self- concept, and external factors such as social position and high identity. Teachers should be highly motivated to be effective teachers. The results show that an effective and good teacher is one who is in the state of development and learning. Qualified teachers are those who are motivated and constantly inspire their learners and colleagues. Good teachers can make changes in education as well as the culture. To put it simply, teacher development is not a linear pass that from point A one conceives point B; it is neither an additive one. Every teacher can have his/her own way of development and learning in a different fashion. We should let the teachers learn and develop.

\section{Implications}

This study yielded significant insights into an English teacher's professional identity construction over two decades. The study enhances our understanding of the process, stages, and motivations behind the cases' identity promotion. The fact has a number of implications for policymakers in that they should provide opportunities for teachers' ongoing professional development, in so far as both professional development and professional identity of teachers go hand in hand. Teachers perceive positive professional identity to the extent that they develop professionally. It is suggested that both policymakers and teacher educators should beware of the repercussions of lower professional identity conceptions of teachers. Teachers' professional identity perceptions, either positive or negative, will affect their instructional practices.

\section{Further research}

The main focus of the study was the transition stages of the participant concerning the level of teaching from teaching at elementary school to university and the motivations behind such transitions. Further study can be limited to the participants who experienced just one stage of transition (e.g., from elementary school to secondary or high school). The design of the current research was a single case study. Additional studies can utilize multiple case study with more participants that experienced a transition in their careers. For the data collection, the researchers applied the interview, stories and dairies. More research may take advantage of the other instruments, such as narrative inquiry or focus group interviews. Regarding the subject matter, the case showed enthusiasm in teaching English. Future studies can consider other subject matters (e.g., science) that the teachers transited to it. Moreover, another transition can consider the methodology and principle of teaching, for example, transition from teaching at classes to teaching online.

Acknowledgements

We would like to appreciate two anonymous reviewers of the study as well as the participant of the study.

\section{Authors' contributions}

The lead author conducted the interviews. The second and third authors codified and analyzed the data. All authors are responsible for all parts of the paper. The author(s) read and approved the final manuscript.

Funding

No funding was available to the present study. 


\section{Competing interests}

The authors declare that they have no competing interests.

\section{Author details}

'Department of English Language, Bonab Branch, Islamic Azad University, Bonab, Iran. ${ }^{2}$ Department of English Language and Literature, Azarbaijan Shahid Madani University, Tabriz, Iran.

Received: 29 January 2020 Accepted: 18 May 2020

Published online: 01 June 2020

\section{References}

Akkerman, S. F., \& Meijer, P. C. (2011). A dialogical approach to conceptualizing teacher identity. Teaching and Teacher Education, 27(2), 308-319.

Armstrong, D., Gosling, A., Weinman, J., \& Marteau, T. (1997). The place of inter-rater reliability in qualitative research: An empirical study. Sociology, 31, 597-606.

Baumeister, R. F., Campbell, J. D., Krueger, J. I., \& Vohs, K. D. (2005). Exploding the self-esteem myth. Scientific American, $292(1), 70-77$.

Beijaard, D., Meijer, P. C., \& Verloop, N. (2004). Reconsidering research on teachers' professional identity. Teaching and Teacher Education, 20(2), 107-128.

Beijaard, D., Verloop, N., \& Vermunt, J. D. (2000). Teacher's perceptions of professional identity: An exploratory study from a personal knowledge perspective. Teaching and Teacher Education, 16(7), 749-764.

Branden, N. (1994). Six pillars of self-esteem. New York: Bantam.

Braun, V., \& Clarke, V. (2006). Using thematic analysis in psychology. Qualitative Research in Psychology, 3(2), 77-101.

Bree, R., \& Gallagher, G. (2016). Using Microsoft Excel to code and thematically analyze qualitative data: a simple, costeffective approach. All Ireland Journal of Teaching and Learning in Higher Education (AISHE-J), 8(2), 2811-28114.

Brookover, W. B., \& Lezotte, L. W. (1979). Changes in schools characteristics coincident with changes in student achievement. East Lansing: Michigan State University. (ERIC Document Reproduction Service No. ED 181 005).

Côté, J. E., \& Levine, C. G. (2002). Identity Formation, Agency, and Culture: A Social Psychological Synthesis. Mahwah: Lawrence Erlbaum. Erikson, E. H. (1968). Identity: Youth and crisis. New York: Norton.

Hood, M. (2011). Case study. In J. Heigham \& A. R. Croker (Eds.), Qualitative research in applied linguistics: a practical introduction. U.K: Palgrave.

Liu, J. (1999). Nonnative-English-speaking professionals in TESOL. TESOL Quarterly, 33(1), 85-102.

Marsh, H. W., Byrne, B. M., \& Yeung, A. S. (1999). Causal ordering of academic self-concept and achievement: Reanalysis of a pioneering study and revised recommendations. Educational Psychologist, 34, 154-157.

Marsh, H. W., \& Martin, A. J. (2011). Academic self-concept and academic achievement: Relations and causal ordering. British Journal of Educational Psychology, 81(1), 59-77.

Marsh, H. W., \& Perry, C. (2005). Does a positive self-concept contribute to winning gold medals in elite swimming? The causal ordering of elite athlete self-concept and championship performances. Journal of Sport and Exercise Psychology, 27, 71-91.

Marsh, H. W., \& Yeung, A. S. (1997a). Causal effects of academic self-concept on academic achievement: Structural equation models of longitudinal data. Journal of Educational Psychology, 89(1), 41-54.

Marsh, H. W., \& Yeung, A. S. (1997b). Coursework selection: The effects of academic self-concept and achievement. American Educational Research Journal, 34(1), 691-720.

McNaughton, S. M., \& Billot, J. (2016). Negotiating academic teacher identity shifts during higher education contextual change. Teaching in Higher Education, 21(6), 644-658 https://doi.org/10.1080/13562517.2016.1163669.

Mead, G. H. (1934). Mind, Self, and Society. U.S.: University of Chicago Press.

Merriam, S. B. (1988). Case study research in education: A qualitative approach. Jossey-Bass.

Nowell, L. S., Norris, J. M., White, D. E., \& Moules, N. J. (2017). Thematic Analysis: Striving to Oaks. CA: SAGE Publications.

Nyström, S. (2009). The Dynamics of Professional Identity Formation: Graduates' Transitions from Higher Education to Working Life. Vocations and Learning, 2, 1-18 https://doi.org/10.1007/s12186-008-9014-.

OECD. (2003). PISA literacy skills for the world of tomorrow - further results from PISA 2000. Paris: OECD and UNESCO.

Pennington, M. C. (2014). Teacher identity in TESOL: A frames perspective. In Y. L. Cheung, S. B. Said, \& P. Kwanghyun (Eds.), Advances and current trends in language teacher identity research (pp. 67-97). New York: Routledge.

Reynolds, J. K. (2015). Social Identity in Social Psychology. International Encyclopedia of the Social \& Behavioral Sciences, 2nd edition, 22, 313-318.

Saldaña, J. (2016). Ethnotheatre: Research from page to stage. Routledge.

Shavelson, R. J., Hubner, J. J., \& Stanton, G. C. (1976). Self-concept: Validation of construct interpretations. Review of Educational Research, 46, 407-441. https://doi.org/10.3102/00346543046003407.

Sinha, S., \& Hanuscin, D. L. (2017). Development of teacher leadership identity: A multiple case study. Teaching and Teacher Education, 63, 356-371.

Stake, R. E. (1995). The art of case study research. Thousand Oaks: Sage Publications.

Tran, A., Burns, A., \& Ollerhead, S. (2017). ELT lecturers' experiences of a new research policy: Exploring emotion and academic identity. System, 67, 65-76.

Valentine, J. C., \& DuBois, D. L. (2005). Effects of self-beliefs on academic achievement and vice-versa: Separating the chicken from the egg. In H. W. Marsh, R. G. Craven, \& D. M. McInerney (Eds.), International Advances in Self Research (Vol. 2, pp. 53-78). Greenwich: Information Age.

Valentine, J. C., DuBois, D. L., \& Cooper, H. (2004). The relations between self-beliefs and academic achievement: A systematic review. Educational Psychologist, 39, 111-133.

Yazan, B. (2018). Toward identity-oriented teacher education: Critical autoethnographic narrative. TESOL Journal, 10(1), 1-15 https://doi.org/10.1002/tesj.388.

\section{Publisher's Note}

Springer Nature remains neutral with regard to jurisdictional claims in published maps and institutional affiliations. 